Supporting Information

\title{
Constructing Thin and Cross-linked Polyimide Membranes by Interfacial Reaction for Efficient $\mathrm{CO}_{2}$ Separation
}

\author{
Xiaochen Xu $u^{\dagger}$, Jie Dong*,†, Xian Xiao ${ }^{\dagger}$, Xin Zhao ${ }^{\dagger}$, Qinghua Zhang ${ }^{\dagger}$
}

$\dagger$ State Key Laboratory for Modification of Chemical Fibers and Polymer Materials, College of Materials Science and Engineering, Donghua University, Shanghai 201620, PR China

*Jie Dong- State Key Laboratory for Modification of Chemical Fibers and Polymer Materials, College of Materials Science and Engineering, Donghua University Email: dj01@dhu.edu.cn

Total number of pages: 5

Total number of schemes: 1

Total number of figures: 3

Total number of tables: 1 

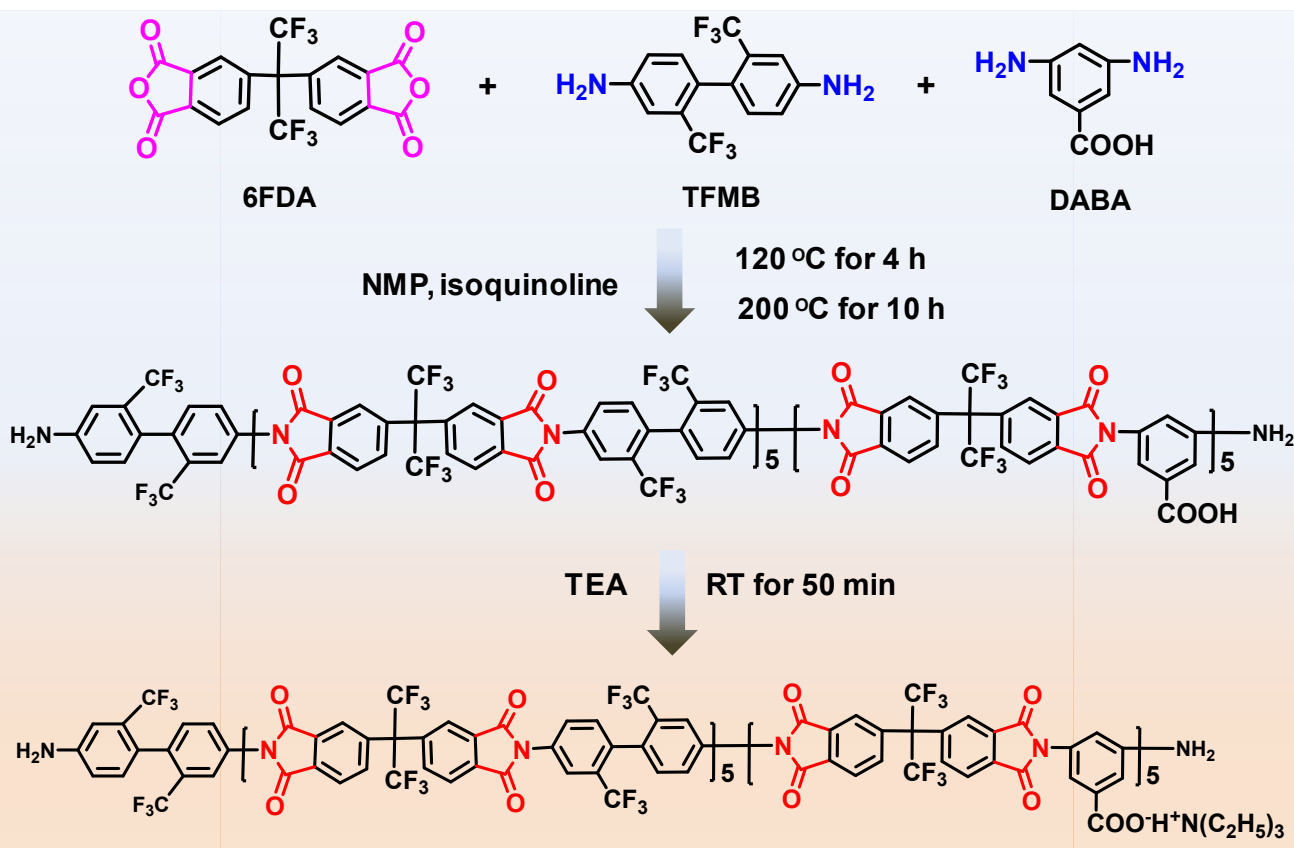

Scheme S1. Synthesis of amine-end-capped PI oligomer and the water-soluble ammonium salt.

Preparation of PDMS-modified PSf flat-sheet support membrane. In this work, the porous PSf membrane was used as substrate. Firstly, PSf particles were dissolved in NMP with a solid content of $25 \%$, then, the viscous solution was scraped on a glass plate and immersed in a water bath at $25{ }^{\circ} \mathrm{C}$ where phase inversion occurred. After $15 \mathrm{~min}$, membranes were transferred to a fresh water bath and left for an hour. Afterwards, the wet membranes were dried in a vacuum oven at $80{ }^{\circ} \mathrm{C}$ for 24 h. Subsequently, the PSf support membranes were modified by a PDMS gutter layers by coating PDMS/heptane solutions composed of $3 \mathrm{wt} \%$ PDMS, $2 \mathrm{wt} \%$ TEOS, and 2 wt $\%$ DBD. Finally, the modified support was cross-linked in a vacuum oven at $75{ }^{\circ} \mathrm{C}$ for $12 \mathrm{~h}$, and the PDMS-modified PSf support membrane could be obtained.

Preparation of PDMS-modified PSf hollow fiber membrane. In present work, a commercially available PSf nanofiltration membrane was utilized as the porous support. The PDMS-coated PSf substrate membrane was produced by a direct dip-coating process. First, the commercial PSf hollow fibers were repeatedly treated by deionized water and dried at $60{ }^{\circ} \mathrm{C}$ in a vacuum oven. Then, it was dipped into the PDMS/heptane solutions composed of $3 \mathrm{wt} \%$ PDMS, $2 \mathrm{wt} \%$ TEOS, and $2 \mathrm{wt} \%$ DBD for a few seconds. Finally, the hollow fiber membrane was cross-linked in a vacuum 
oven at $75{ }^{\circ} \mathrm{C}$ for $12 \mathrm{~h}$, and the PDMS-modified PSf hollow fiber membranes were prepared.

Table S1. Solubility of synthesized polyimide in various solvents a

\begin{tabular}{ccccccccc}
\hline NMP & DMAc & DMF & DMSO & m-cresol & THF & $\mathrm{CHCl}_{3}$ & Methylbenzene & Xylene \\
\hline++ & ++ & ++ & ++ & ++ & +- & -- & -- & -- \\
\hline
\end{tabular}

${ }^{\text {a }}$ Qualitative solubility was measured with $1 \mathrm{mg}$ of a sample in $1 \mathrm{~mL}$ of organic solvent. ++ Soluble at room temperature; +- Partially soluble at room temperature; -- insoluble.

(A)

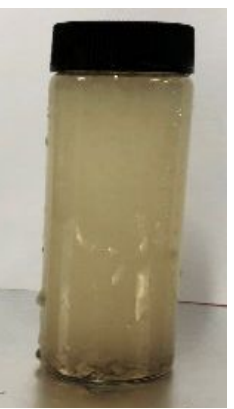

$\mathrm{PI}-\mathrm{NH}_{2}$ aqueous solution
TEA

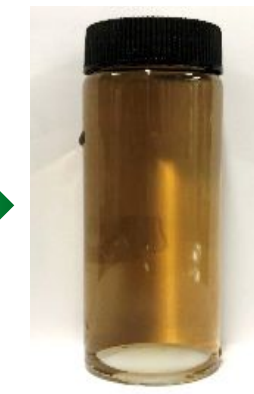

(B)

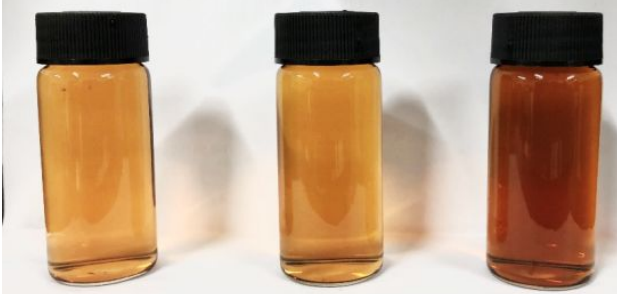

$10 \mathrm{mmol} / \mathrm{L} \quad 20 \mathrm{mmol} / \mathrm{L} \quad 60 \mathrm{mmol} / \mathrm{L}$

\section{$\mathrm{PI}-\mathrm{NH}_{2}$ ammonium salt} aqueous solution

Figure S1. (A) Dissolution of $\mathrm{PI}-\mathrm{NH}_{2}$ oligomer and the oligomer ammonium salt in water, and (B) $\mathrm{PI}-\mathrm{NH}_{2}$ oligomer ammonium salt aqueous solution with different solid concentrations. 


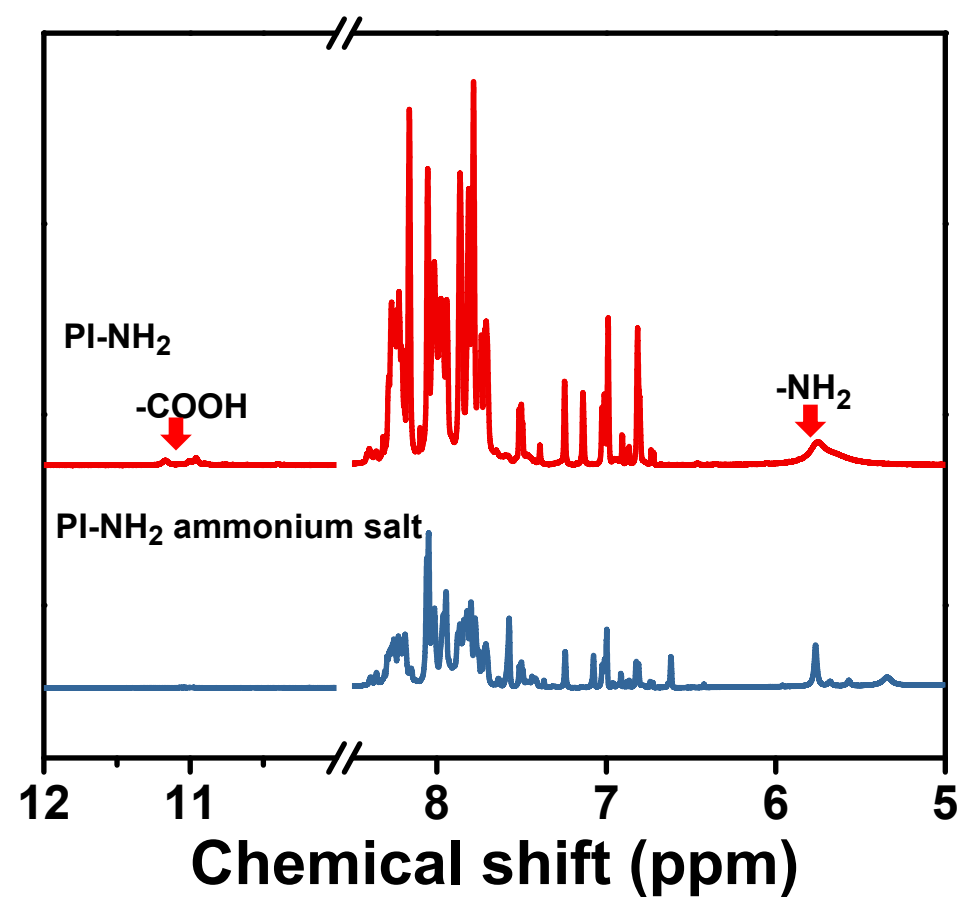

Figure S2. ${ }^{1} \mathrm{H}-\mathrm{NMR}$ of $\mathrm{PI}-\mathrm{NH}_{2}$ and $\mathrm{PI}-\mathrm{NH}_{2}$ oligomer ammonium salt.

The barrier of the selective layer to the gas molecule can be approximately regarded as a resistance, which can be regarded as:

$$
\begin{aligned}
Q_{i} & =\frac{\Delta P}{R} \\
R & =\frac{l}{A P}
\end{aligned}
$$

$R$ is the resistance to permeate flow, $A$ is the surface area of testing membranes, $l$ is the thickness of membrane through which the component permeates and $P$ represents the permeability of membrane. When the PSf/PDMS support is coated with cross-linked PI selective layer, the resistance model can be expressed as shown in Figure S3(A) where the $R_{1}$ is the resistance of the PI layer to permeate gas flow. The relationship between $R_{1}, R_{2}, R_{3}, R_{4}$ and $R_{5}$ which describes the total resistance of the TFC membrane, analogous to the relationship between resistances in an electrical circuit, is expressed as follows:

$$
R_{T F C}=R_{1}+R_{2}+\frac{R_{3} R_{4}}{R_{3}+R_{4}}+R_{5} \approx R_{1}+R_{2}
$$

Combing Eq. (1) in main article and Eq. (S1), the gas permeation fluxes $(J)$ can be regarded as: 


$$
J=\frac{1}{A R}
$$

Combing Eq. (S3) and (S4), the resistance of PI selective layer can be expressed as:

$$
R_{1}=\frac{1}{A_{T F C} J_{T F C}}-\frac{1}{A_{2} J_{2}}
$$

Because the area of PI layer and PDMS layer is approximately equal $\left(A_{T F C} \approx A_{2}\right)$, the formula can be further simplified as:

$$
R_{1}=\frac{1}{A}\left(\frac{1}{J_{T F C}}-\frac{1}{J_{P D M S}}\right)
$$

Accordingly, the relationship between the gas permeability and permeance of PI layer is shown as following when combining Eq. (S2) and (S6):

$$
P_{1}=l_{1}\left(\frac{1}{J_{T F C}}-\frac{1}{J_{2}}\right)^{-1}
$$

Accordingly, the gas permeability coefficient can be calculated through Eq. (S7), combined with the permeability flux of composite membrane only coated with PDMS layer $\left(J_{2}\right)$, the permeability flux coated with PI layer $\left(J_{\mathrm{TFC}}\right)$ and the thickness of PI layer $\left(l_{1}\right)$.
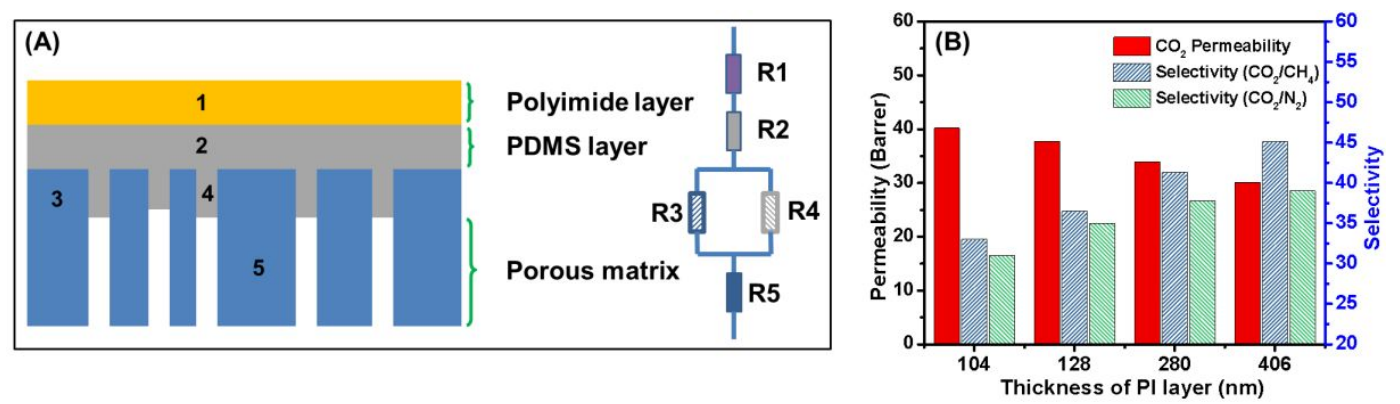

Figure S3. (A) A resistance-in-series model for the PSf/PDMS/PI TFC membranes, and (B) permeability of the PSf/PDMS/PI TFC membrane depended on the thickness of PI selective layer. 